The Egyptian Journal of Hospital Medicine (January 2019) Vol. 74 (4), Page 885-889

\title{
Assessment of Impact of Insight on Medication Adherence in Schizophrenic Patients
}

\author{
Abd Elhady E. Hassan, Ali Abd E. Elnabawy, Mohamed M. A. Eldeeb, Ahmed S. M. Essa
}

Departments of Psychiatry and Neurology - Faculty of Medicine - Al-Azhar University.

\begin{abstract}
BACKGROUND: Many patients with schizophrenia have impaired insight and low medication adherence. Poor adherence is one of the leading problems affecting the effectiveness of treatment in schizophrenia. It is an identified factor for relapse and hospitalizations with major social and economic consequences.

OBJECTIVE: The aim of this study was to study the relation between insight and medication adherence and
\end{abstract} other factors that may affect both of them.

SUBJECT AND METHODS: A total number of 50 schizophrenic outpatients "DSM 5" aged > 18 years old who were attending the hospital for regular follow up were included in this study. From the selected patients full medical history was obtained including: name, age, gender, occupation, educational status, history of the psychiatric disease, duration, medical treatment and times of hospitalization. Cultural and social standard and degree of family support was also collected. Patients' insight was measured by the Schedule for Assessment of Insight-Expanded Version (SAI-E) translated into Arabic by Marwa Abdelgawad. The degree of medication adherence was measured by using Medication Adherence Rating Scale (MARS).

RESULTS: There was no significant correlation between patients' insight and patients' ages, duration of illness and hospitalization times with p-value: $0.69,0.61$ and 0.07 respectively. In addition, there was no significant association between medication adherence and age, duration of illness, number of hospitalization, gender, social level and family support with p-value: $0.575,0.678,0.566,0.945,0.091$ and 0.360 respectively. Our results showed a strong positive correlation between insight and medication adherence with p-value: $<0.0001$.

CONCLUSION: Insight and adherence were found to be closely related, low insight was associated with poor adherence in patients with schizophrenia. Moreover, these results should be used to establish a strategy for improving the prognosis of chronic schizophrenia.

Keywords: Medication adherence, Insight, Neurocognition, Schizophrenia.

INTRODUCTION

Adherence to medication is a subject of increasing interest for clinicians studying diseases with chronic conditions such as schizophrenia. Nonadherence or poor adherence is a major concern in the effectiveness of antipsychotic treatment in schizophrenic patients. It represents a poor prognostic factor for schizophrenia, according to the increasing risk of relapse and hospitalization ${ }^{(\mathbf{1})}$.

Medication nonadherence of patients with schizophrenia was found to be associated with poor outcomes including rate of relapse, rehospitalization, and poor long-term functional outcomes. Many studies have particularly pointed out that medication nonadherence during the early stage of schizophrenia increases the risk for relapse and re-hospitalization ${ }^{(2)}$.

It has been well established that the causes of non-adherence are multifactorial. Many studies have attempted to identify factors that can predict medication non-adherence, which could be possible

Received: $13 / 10 / 2018$

Accepted: 02/11/2018 targets for improving adherence. Factors that contribute to medication non-adherence include a lack of insight or the inability to understand one's illness, persistent psychotic symptoms, co-occurring of a substance abuse and comorbid conditions ${ }^{(3)}$.

Lack of insight has also been related to various outcomes of schizophrenia, including increased number of hospitalizations, poor functioning, and poor quality of life ${ }^{(2)}$.

The aim of the work was to estimate the impact of insight on adherence to medication based on a population of patients in Abbassia Hospital who had the diagnosis of schizophrenia.

\section{SUBJECTS AND METHODS}

This is a cross-sectional non-interventional study that had been carried out in Psychiatry Department, Al Azhar University. The study was approved by the Ethics Board of Al-Azhar University. 


\section{Assessment of Impact of Insight on Medication Adherence in Schizophrenic Patients}

Before the start of the study, permission was obtained from Ethical Committee of the Faculty of Medicine, Al-Azhar University and Abbasia Hospital for Mental Health and Addiction Treatment. Moreover, informed written consents from patients included in the study was obtained.

Subjects: A total number of 50 schizophrenic outpatients who were attending the hospital for regular follow up according to the following criteria:

* Inclusion Criteria: aged >18 years old, schizophrenic "DSM 5".

* Exclusion criteria: all cases that had not satisfy the inclusion criteria were excluded.

- Methods: All subjects of the study were subjected to the following:-

A. Full medical history including:

i. Name, age, gender, occupation and educational status.

ii. History of the psychiatric disease, duration, medical treatment, times of hospitalization.

iii. Cultural and social standard.

iv. Degree of family support.

B. Patients' insight was measured by the Schedule for Assessment of Insight - Expanded Version (SAI-E) translated into Arabic by Marwa Abdelgawad ${ }^{(4)}$.

C. Degree of medication adherence was measured by using Medication Adherence Rating Scale (MARS).

Statistical Analysis: Data were analyzed with SPSS version 15.0 (statistical package for the Social Science, Chicago, IL). Quantitative data were expressed as mean \pm standard deviation (SD) or standard error (SE). $\mathrm{SE}=\mathrm{SD} /$ square root of patients number which was used in case of big SD. Data were analyzed by independent sample, paired test. Pvalue was considered significant if $<0.05$ and highly significant if $<0.001$.

\section{RESULTS}

Our study was conducted on 50 schizophrenic "DSM 5" patients, $64 \%$ were male and $36 \%$ were female with mean age of $40.58 \pm 9.5$ years and ranging between 22 to 57 years old. The mean duration of illness was $15.02 \pm 8.6$ years and ranging between $2-37$ years. It was also found that the mean hospitalization time was $3.46 \pm 2.28$.

Regarding socioeconomic standard, $50 \%$ were of moderate standard, and 50\% were of low standard. Regarding family support, 29 patients " $58 \%$ " had a moderate support, 19 patients "38\%" were below moderate and only 2 patients " $4 \%$ " had a good support (table 2).

Regarding degree of insight, we found that the mean value was $11.92 \pm 5.6$ and ranging between 3 24 . These results indicate poor insight in majority of our patients as shown in table (1).

Regarding degree of medication adherence, our results showed that the mean score of our patients was $5.36 \pm 2.17$ indicating moderate medication adherence (TABLE 2).

There was no significant correlation between patients' insight and patients' ages, duration of illness and hospitalization times with p-value: 0.69, 0.61 and 0.07 respectively.

Table (1): Association between patients' insight and medication adherence and other variables.

\begin{tabular}{|c|c|c|c|c|c|c|}
\hline \multirow[t]{2}{*}{ variable } & \multicolumn{2}{|c|}{ Age } & \multicolumn{2}{|c|}{$\begin{array}{c}\text { Duration of } \\
\text { illness }\end{array}$} & \multicolumn{2}{|c|}{$\begin{array}{c}\text { Hospitalization } \\
\text { times }\end{array}$} \\
\hline & $\begin{array}{c}\text { r- } \\
\text { value }\end{array}$ & $\begin{array}{c}p- \\
\text { value }\end{array}$ & $\begin{array}{c}\text { r- } \\
\text { value }\end{array}$ & $\begin{array}{c}p- \\
\text { value }\end{array}$ & $\begin{array}{c}\text { r- } \\
\text { value }\end{array}$ & $\begin{array}{c}p- \\
\text { value }\end{array}$ \\
\hline Insight & 0.056 & 0.698 & 0.074 & 0.610 & $\overline{0.255}$ & 0.074 \\
\hline $\begin{array}{l}\text { Medication } \\
\text { adherence }\end{array}$ & 0.081 & 0.575 & $\stackrel{-}{0.060}$ & 0.678 & -0.083 & 0.566 \\
\hline $\begin{array}{l}\quad \text { Our } \\
\text { significant } \\
\text { adherence } \\
\text { hospitaliza } \\
\text { support w } \\
0.091 \text { and }\end{array}$ & $\begin{array}{l}\text { results } \\
\text { assc } \\
\text { and ag } \\
\text { tion, g } \\
\text { ith } \mathrm{p}-\mathrm{v} \\
0.360 \mathrm{r}\end{array}$ & $\begin{array}{l}\text { showe } \\
\text { ciation } \\
\text { e, dura } \\
\text { ender, } \\
\text { lue: } 0 . \\
\text { spectiv }\end{array}$ & $\begin{array}{l}\text { d tha } \\
\text { bet } \\
\text { ion of } \\
\text { social } \\
575,0 \\
\text { ely. }\end{array}$ & $\begin{array}{l}\text { there } \\
\text { een } \\
\text { llness, } \\
\text { level } \\
78,0 .\end{array}$ & $\begin{array}{l}\text { were } \\
\text { medica } \\
\text { numbe } \\
\text { and fal } \\
566,0 .\end{array}$ & $\begin{array}{l}\text { no } \\
\text { ion } \\
\text { of } \\
\text { iily } \\
45 \text {, }\end{array}$ \\
\hline
\end{tabular}

Table (2): Association between medication adherence and family support and socioeconomicstandrad.

\begin{tabular}{|c|c|c|c|c|c|}
\hline $\begin{array}{c}\text { Family } \\
\text { Support }\end{array}$ & $\begin{array}{c}\text { Below } \\
\text { moderate }\end{array}$ & moderate & good & t-test & $\begin{array}{c}\text { p- } \\
\text { value }\end{array}$ \\
\hline $\begin{array}{c}\text { Medication } \\
\text { adherence }\end{array}$ & $\begin{array}{c}\mathbf{5 . 3 7} \pm \\
\mathbf{2 . 4 7}\end{array}$ & $\begin{array}{c}\mathbf{5 . 2 1} \pm \\
\mathbf{1 . 9 8}\end{array}$ & $\begin{array}{c}\mathbf{7 . 5} \pm \\
\mathbf{0 . 7 1}\end{array}$ & $\mathbf{1 . 0 4 3}$ & $\mathbf{0 . 3 6 0}$ \\
\hline $\begin{array}{c}\text { Socioeconomic } \\
\text { standard }\end{array}$ & low & moderate & t-test & $\begin{array}{c}\text { p- } \\
\text { value }\end{array}$ \\
\hline $\begin{array}{c}\text { Medication } \\
\text { adherence }\end{array}$ & $\mathbf{4 . 8 4} \pm \mathbf{2 . 3 4}$ & $\mathbf{5 . 8 8} \pm \mathbf{1 . 9}$ & - & $\mathbf{1 . 7 2}$ & $\mathbf{0 . 0 9 1}$ \\
\hline $\begin{array}{c}\text { Gender } \\
\text { Medication }\end{array}$ & Male $(\mathrm{No}=32)$ & Female(No=18) & t-test & $\begin{array}{c}\text { p- } \\
\text { value }\end{array}$ \\
\hline \begin{tabular}{c} 
adherence \\
\hline
\end{tabular} & $\mathbf{2 . 3 1} \pm \mathbf{5 . 3 4}$ & $\mathbf{1 . 9 8} \pm \mathbf{5 . 3 9}$ & - & $\mathbf{0 . 0 7}$ & $\mathbf{0 . 9 4 5}$ \\
\hline
\end{tabular}

Linear regression analysis showed that family support had a significant relation with medication adherence with p-value: 0.028 . 
Our results showed a strong positive correlation between insight and medication adherence with pvalue: $<0.0001$ as shown in figure (1).

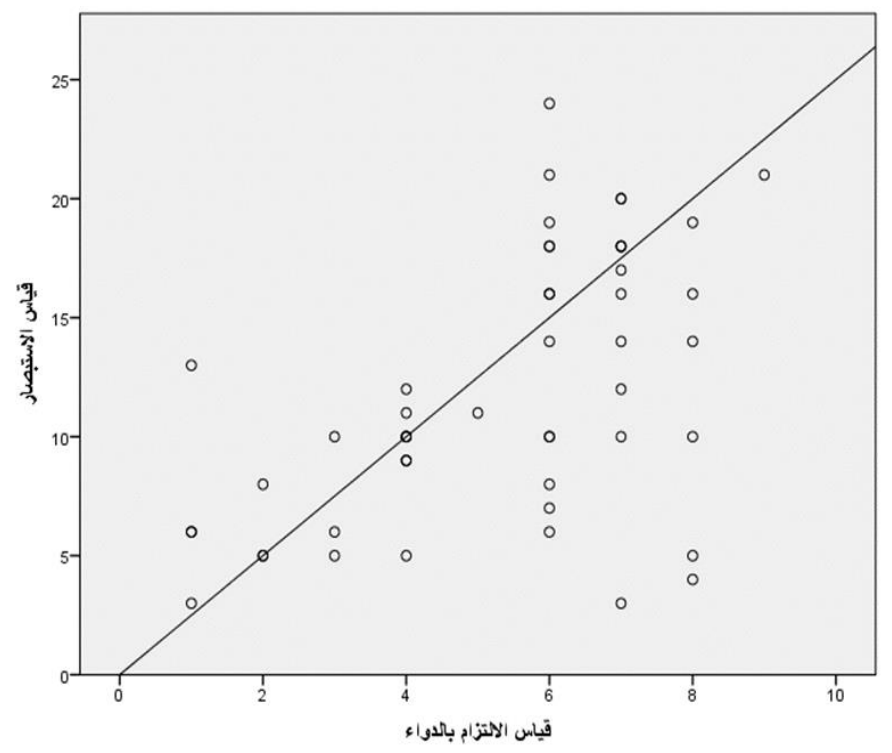

Figure (1): Diagram showing positive correlation between insight and medication adherence.

\section{DISCUSSION}

Rates of medication non-adherence among patients with schizophrenia have been estimated at approximately $50 \%$, leading to higher rates of relapse and hospitalization as well as to decreasing clinical, cognitive and functional prognosis ${ }^{(5)}$.

Lack of adherence to treatment in patients with schizophrenia is a major risk factor for poor outcome including relapse, re-hospitalization, and suicide. Poor insight into illness may be a leading cause for partial or non-adherence since a high proportion of patients with schizophrenia are partially or completely unaware of their mental disorder ${ }^{(\boldsymbol{6})}$.

Degree of insight in our patients was evaluated and assessed by the Expanded Version of the Schedule of Assessment of insight (SAI-E). We found that the mean value was $11.92 \pm 5.6$ indicating poor insight in majority of our patients.

These results were in agreement with Choudhury et al. ${ }^{(7)}$ who reported in their study on 30 patients of both sexes diagnosed to have schizophrenia that about $70 \%$ of the subjects possessed poor awareness of their mental disorder and concluded that majority of schizophrenic patients possess poor insight. Also, Schennach et al. (8) and Lehrer and Lorenz ${ }^{(9)}$ reported that poor insight is a core attribute of schizophrenia occurring in $57-98 \%$ of patients. While Baier ${ }^{(\mathbf{1 0})}$ reported that about $30 \%$ to $50 \%$ of people with schizophrenia experience lack of insight.

The degree of adherence to medications and treatment was assessed by using the Medication Adherence Rating Scale "MARS". Our results showed that the mean score of our patients was 5.36 \pm 2.17 indicating moderate medication adherence.

Our results was in similarity with that of Tessier $\boldsymbol{e t}$ al. ${ }^{(11)}$ who reported in their multicenter study on 72 schizophrenia patients that medication adherence was moderate according to MARS with average score $5.63 \pm 1.86$. In addition, Novick et al. (12) reported in their study on 612 schizophrenia patients that the mean value of medication adherence according to the MARS was $\mathbf{5 . 8} \mathbf{\mathbf { 2 } . 7}$ indicating moderate medication adherence in their study.

Regarding factors that may affect patients' awareness by his mental disease "patients' insight". Our results showed that no significant correlation between patients' insight and patients' ages, duration of illness and hospitalization times with p-value: $0.69,0.61$ and 0.07 respectively.

Regarding age, our results was in agreement with Novick et al. ${ }^{(12)}$ who found no significant relationship between age and insight into illness in schizophrenia with r-value: 0.12 and p-value: 0.395 .

Against us was Braw et al. ${ }^{(14)}$ who found a significant correlation between age and insight into illness with, r-value: -0.36 and p-value: $<0.01$.

Regarding duration of illness, our results were in agreement with what was reported by Saravanan et al. ${ }^{(14)}$ that the duration of illness and gender were not determinants of insight in schizophrenia patients.

In order to evaluate factors affecting medication adherence in our study, a statistical analysis was done to discover the significant association between the medication adherence and the other factors. Our results showed that there were no significant association between medication adherence and age, duration of illness, number of hospitalization, gender, social level and family support with p-value: $0.575,0.678,0.566,0.945,0.091$ and 0.360 respectively.

In the study done by Yen et al. ${ }^{(15)}$, they showed that no significant correlation was observed between medication adherences in 74 schizophrenic subjects 
and age, duration of illness and number of previous admission to hospital with r-value: $0.159,0.049$, and 0.003 respectively and their p-value was $>0.05$.

In the study done by Lacro et al. (16) they reported that age, gender, ethnicity, marital status, education level, neurocognitive impairment, severity of psychotic symptoms, severity of medication side effects, higher antipsychotic dose, presence of mood symptoms, route of medication administration and family involvement were not found to be consistent predictors of non-adherence.

Acosta et al. ${ }^{(17)}$ reported that non-adherence was reported to be more frequent in men than in women, though not in all of the relevant studies.

Linear regression analysis showed that family support had a significant relation with medication adherence. This could be explained by that family support was a predictor of good medication adherence only for a short period of time, since these patients required persistent family support to stay on medication ${ }^{(17)}$.

Regarding patients' insight into illness and its effect on medication adherence in schizophrenia patients', our results showed a strong positive correlation between insight and medication adherence. This means that greater insight was associated with higher medication adherence.

Similar to our results was Tessier et al. ${ }^{(11)}$ who reported that greater adherence was correlated with higher insight, and the data fit a model in which medication adherence was directly predicted by insight, therapeutic alliance and perceived trauma related to psychiatric treatment. Medication adherence could be enhanced by by increasing insight.

In addition, Novick et al. (12) reported that Insight, therapeutic alliance with the treating psychiatrist and medication adherence were highly correlated in patients with schizophrenia and those three factors co-vary during the course of the disorder and an improvement in one is accompanied by improvements in the others.

Bitter et al. (10) also found in their crosssectional, non-interventional study on 262 patients distributed across 13 sites that the primary logistic regression analysis indicated a significant relationship between the total score on the SAI scale and the Compliance Scale (Spearman correlation =
0.58; $\mathrm{p}<0.0001$ ), which supported the hypothesis that the level of insight and compliance are strongly associated.

\section{CONCULSION}

Insight and adherence were found to be closely related, low insight are associated with poor adherence in patients with schizophrenia. These results should be used to establish a strategy for improving the prognosis of chronic schizophrenia.

\section{REFERENCES}

1. Misdrahi D, Petit M, Blanc O et al. (2012): The influence of therapeutic alliance and insight on medication adherence in schizophrenia. Nord. J. Psychiatry, 66:49-54.

2. Chan KW, Hui LM, Wong HY et al. (2014): Medication adherence, knowledge about psychosis, and insight among patients with a schizophrenia-spectrum disorder. J. Nerv. Ment. Dis., 1:25-9.

3. Na E, Yim SJ, Lee JN et al. (2015): Relationships among medication adherence, insight, and neurocognition in chronic schizophrenia. Psychiatry Clin. Neurosci., 5:298-304.

4. Mousa M (2010): The effect of "Drug compliance therapy" on the compliance attitude toward medication and insight among hospitalized psychiatric patients. Unpublished doctor thesis, Alexandria University, Faculty of Nursing.

5. Velligan D, Weiden P, Sajatovic $M$ et al. (2009): Expert consensus panel on adherence problems in serious and persistent mental illness. J. Clin. Psychiatry, 70; 4:1-46.

6. Baier M (2010): Insight in schizophrenia: a review. Curr. Psychiatry Rep., 12(4):356-61.

7. Choudhury $S$, Khess CR, Bhattacharyya $R$ et al. (2009): Insight in schizophrenia and its association with executive functions. Indian $\mathrm{J}$. Psychol. Med., 31(2):71-6.

8. Schennach R, Meyer S, Seemüller F et al. (2012): Insight in schizophrenia-course and predictors during the acute treatment phase of patients suffering from a schizophrenia spectrum disorder. Eur. Psychiatry, 27:62533. 
9. Lehrer DS and Lorenz J (2014): Anosognosia in schizophrenia: hidden in plain sight. Innov. Clin. Neurosci., 11(5-6):10-7.

10. Bitter I, Fehér L, Tényi T et al. (2015): Treatment adherence and insight in schizophrenia. Psychiatr. Hung., 30(1):18-26.

11. Tessier A, Boyer L, Husky M et al. (2017): Medication adherence in schizophrenia: The role of insight, therapeutic alliance and perceived trauma associated with psychiatric care. Psychiatry Research, 257:315-321.

12. Novick D, Montgomery $\mathrm{W}$, Treuer $\mathrm{T}$ et al. (2015): Relationship of insight with medication adherence and the impact on outcomes in patients with schizophrenia and bipolar disorder: results from a 1-year European outpatient observational study. BMC Psychiatry, 15:189.
13. Gerretsen $P$, Chakravarty MM, Mamo D et al. (2013): Frontotemporoparietal asymmetry and lack of illness awareness in schizophrenia. Hum. Brain Mapp., 34:1035-1043.

14. Saravanan B, Jacob KS, Johnson $S$ et al. (2007): Assessing insight in schizophrenia: East meets West. Br. J. Psychiatry, 190:243-7.

15. Yen CF, Chen CS, Ko CH et al. (2005): Relationships between insight and medication adherence in outpatients with schizophrenia and bipolar disorder: Prospective study. Psychiatry and Clinical Neurosciences, 59:403-409.

16. Lacro JP, Dunn LB, Dolder CR et al. (2002): Prevalence of and risk factors for medication nonadherence in patients with schizophrenia: a comprehensive review of recent literature. J. Clin. Psychiatry, 63(10):892-909.

17. Acosta FJ, Hernández JL, Pereira J et al. (2012): Medication adherence in schizophrenia. World J. Psychiatry, 2(5):7482. 